Tobacco Control Research Group, Department for Health, University of Bath, Bath, UK

Correspondence to: A B Gilmore abcg20@bath.ac.uk Cite this as: BMJ 2020;370:m3528 http://dx.doi.org/10.1136/bmj.m3528 Published: 16 September 2020

\title{
US regulator adds to confusion around heated tobacco products
}

\author{
Tobacco manufacturer exploits FDA's ambiguous ruling
}

\section{Anna B Gilmore, ${ }^{1}$ Sophie Braznell ${ }^{1}$}

The emergence of new consumer tobacco and nicotine products, notably electronic cigarettes and heated tobacco products, ${ }^{1}$ has produced controversy and confusion. This is partly because the two products are often conflated, not least by Philip Morris International, the world's largest tobacco company. ${ }^{2}$ With global sales of cigarettes inexorably declining, the company's future now depends on IQOS, its flagship heated tobacco product. $^{23}$

Yet e-cigarettes and heated tobacco products are quite different. E-cigarettes contain no tobacco but heat nicotine-containing liquids to produce an inhalable aerosol. They can (with behavioural support) help smokers quit ${ }^{4}$ and, while not safe, are currently considered a less harmful alternative to smoking for those who switch fully. ${ }^{45}$ By contrast, IQOS (sold through Altria in the US), which heats small cigarette-like tobacco sticks, has not been shown to enable quitting or to be significantly lower risk than smoking. ${ }^{1}$

Confusion has now been escalated by the US Food and Drug Administration's recent decision about the status of IQOS under its "modified risk tobacco product" criteria. ${ }^{6}$ The poorly titled criteria actually comprise two different standards-risk modification and exposure modification. The FDA denied risk modification status for IQOS, clearly stating that Phillip Morris "has not demonstrated that [IQOS] will significantly reduce harm and the risk of tobacco-related disease." ${ }^{6}$ Instead the FDA granted only its lower exposure modification status. ${ }^{6}$

Phillip Morris was nevertheless quick to misrepresent the decision as a "milestone for public health," qualifying that although officially authorised as a modified risk tobacco product it did not meet the FDA's risk modification criteria. ${ }^{7}$ The company immediately launched a global public relations campaign using the decision to push other governments to open their markets to or relax rules regulating IQOS. ${ }^{78}$ encouraged the Philippines to adopt the FDA decision as a "starting block" for public health policy making. ${ }^{8}$

\section{Minefield}

How do consumers and regulators attempt to make sense of this minefield? The short answer is there is little role for heated tobacco products at either individual or population level. The fuller answer is they need to understand the FDA's complex decision.

For individual smokers, decisions about new products are reasonably straightforward-if the product helps them quit or is genuinely less harmful than smoking, it can (if used exclusively) reduce health risks. With no evidence that IQOS helps quitting, smokers wishing to quit should stick with evidence based smoking cessation interventions. On harm, the FDA decision ${ }^{6}$ is broadly in line with the evidence to date that IQOS exposes users to lower levels of some harmful substances than cigarette smoke but this does not result in reduced disease risk compared with cigarette smoking. ${ }^{19}$

For example, independent analyses of Phillip Morris's clinical data show that switching from smoking to IQOS does not lead to significant improvements in pulmonary inflammation and function or in biomarkers predictive of major illness. ${ }^{10}{ }^{11}$ Yet in granting the exposure modification order, the FDA is required to consider it "reasonably likely" that future studies will show reductions in mortality and morbidity compared with ongoing smoking. ${ }^{6}$ This is arguably possible since the longest trial ( 26 weeks) may be too short to identify potential benefits.

However, caution is needed. Phillip Morris's clinical and aerosol outcome data are not comprehensive, and in fact 56 potentially harmful substances are higher in IQOS aerosol than cigarette smoke. ${ }^{6} 12$ Concerns about Phillip Morris's IQOS research ${ }^{13} 14$ and failure to make data from its longer term studies public $^{15}{ }^{16}$ are amplified by the tobacco industry's history of research manipulation and hiding the harms of smoking. ${ }^{1317}$ With the many other products now available, including pharmaceutical nicotine, which are known to be safe, smokers looking to reduce harm rather than quit should see heated tobacco products as a last resort.

\section{Regulatory confusion}

For regulators, the risk-benefit calculation is more complex. Even the introduction of products genuinely less risky than cigarettes may lead to population level harm if taken up by large numbers of people who would never have smoked cigarettes. Here, the FDA's decision is most surprising because it is required to determine that even its exposure modification order will benefit population health. ${ }^{6}{ }^{9}$ That is highly contestable given the absence of evidence on quitting, the evidence on harm, and because uptake among young, non-smokers seems inevitable given Phillip Morris's documented marketing. ${ }^{218}$ Indeed, the Australian regulator has since reached the opposite conclusion stating, "I do not consider that HTPs [heated tobacco products] would make a significant contribution to population harm reduction." 19 Regulators must also recognise that a focus on heated tobacco products may distract them from the evidence based measures known to reduce tobacco use at scale. $^{20}$

For once we should perhaps leave the last word with Phillip Morris, which discreetly (page 17, FDA application summary) acknowledges: "It has not been 
demonstrated that switching to the iQOS system reduces the risk of developing tobacco-related diseases compared to smoking cigarettes." ${ }^{21}$ Until that changes, heated tobacco products have no public health role. Governments should resist pressure to open their markets to these products and, where already present, should regulate both the heating device and the tobacco sticks as tobacco products, in line with World Health Organization's

recommendations. ${ }^{22}$ The FDA should make its terminology clearer to ensure products which meet only reduced exposure criteria cannot be misrepresented as reduced harm.

Competing interests: We have read and understood BMJ policy on declaration of interests and declare support from Bloomberg Philanthropies' Stopping Tobacco Organizations and Products. The funders had no role in the study design, data collection and analysis, decision to publish, or preparation of the manuscript.

Provenance and peer review: Not commissioned; externally peer reviewed.

1 Jankowski M, Brożek GM, Lawson J, Skoczyński S, Majek P, Zejda JE. New ideas, old problems? Heated tobacco products-a systematic review. Int J Occup Med Environ Health2019;32:595-634. doi: 10.13075/ijomeh.1896.01433. pmid: 31584041

2 Evans-Reeves K, ed. Addiction at any cost: Philip Morris International uncovered. 2020. https://exposetobacco.org/wp-content/uploads/STOP_Report_Addiction-At-Any-Cost.pdf

3 Gilmore A, Branston R. Philip Morris International: the beginning of the end? 5 May 2020. https://exposetobacco.org/news/pmi-agm/

4 Hajek P, Phillips-Waller A, Przulj D, etal. A randomized trial of e-cigarettes versus nicotine-replacement therapy. N Engl J Med 2019;380:629-37. doi: 10.1056/NEJMoa1808779. pmid: 30699054

5 National Academies of Sciences, Engineering and Medicine. Public health consequences of e-cigarettes. 2018. https://www.nap.edu/catalog/24952/public-health-consequences-of-e-cigarette

6 US Food and Drug Administration. Scientific review of modified risk tobacco product application (MRTPA) under section 911(d) of the FD\&C Act-technical project lead. 7 July 2020. https://www.fda.gov/media/139796/download

$7 \quad$ Philip Morris International. FDA authorizes marketing of IQOS as a modified risk tobacco product. Press release, 7 Jul 2020. https://www.pmi.com/media-center/press-releases/press-details/?newsld=22631

8 Tobacco Tactics. PMI promotion of IQOS using FDA MRTP order. 14 Aug 2020. https://tobaccotactics.org/wiki/pmi-iqos-fda-mrtp-order/

9 Lempert LK, Glantz S. Analysis of FDA's IQOS marketing authorisation and its policy impacts. Tob Control 2020:tobaccocontrol-2019-055585. [Epub ahead of print.] doi: 10.1136/tobaccocontrol-2019-055585. pmid: 32601147

10 Moazed F, Chun L, Matthay MA, Calfee CS, Gotts J. Assessment of industry data on pulmonary and immunosuppressive effects of IQOS. Tob Control 2018;27(suppl 1):S20-5. doi: 10.1136/tobaccocontrol-2018-054296. pmid: 30158203

11 Glantz SA. PMI's own in vivo clinical data on biomarkers of potential harm in Americans show that IQOS is not detectably different from conventional cigarettes. Tob Control 2018;27(suppl 1):s9-12. doi: 10.1136/tobaccocontrol-2018-054413. pmid: 30131374

12 St Helen G, Jacob lii P, Nardone N, Benowitz NL. IQOS: examination of Philip Morris International's claim of reduced exposure. Tob Control 2018;27(suppl 1):s30-6. doi: 10.1136/tobaccocontrol-2018-054321. pmid: 30158205

13 Organized Crime and Corruption Reporting Project. Unsmoking for health, 25 May 2020 https://www.occrp.org/en/loosetobacco/blowing-unsmoke/unsmoking-for-health

14 Lasseter T, Bansal P, Wilson T, et al. Scientists describe problems in Philip Morris e-cigarette experiments. Reuters2017 Dec 20. https://www.reuters.com/investigates/special-report/tobaccoiqos-science/

15 Sponsiello-Wang Z, Langer P, Prieto L, etal. Household surveys in the general population and web-based surveys in IQOS users registered at the Philip Morris International IQOS user database: protocols on the use of tobacco- and nicotine-containing products in Germany, Italy, and the United Kingdom (Greater London), 2018-2020. JMIR Res Protoc 2019;8:e12061. doi: 10.2196/12061. pmid: 31094340

16 Ansari SM, Lama N, Blanc N, etal. Evaluation of biological and functional changes in healthy smokers switching to the tobacco heating system 2.2 versus continued tobacco smoking: protocol for a randomized, controlled, multicenter study. JMIR Res Protoc 2018;7:e11294. doi: 10.2196/11294. pmid: 30143474

17 Bero LA. Tobacco industry manipulation of research. Public Health Rep 2005;120:200-8. doi: 10.1177/003335490512000215. pmid: 15842123

18 Jackler R, Ramamurthi D, Axelrod A, et al. Global marketing of IQOS: the Philip Morris campaign to popularize "heat not burn" tobacco. 2020. http://tobacco.stanford.edu/tobacco_main/publications/IQ0S_Paper_2-21-2020F.pdf

19 Australian Therapeutic Goods Administration. Notice of final decisions to amend (or not amend) the current poisons standard, 24 Aug 2020

20 Chung-Hall J, Craig L, Gravely S, Sansone N, Fong GT. Impact of the WHO FCTC over the first decade: a global evidence review prepared for the Impact Assessment Expert Group. Tob Control 2019;28(Suppl 2):s119-28. doi: 10.1136/tobaccocontrol-2018-054389. pmid: 29880598
21 Philip Morris International. MRTPA Section 27 Executive Summary. 2017. https://www.fda.gov/media/105437/download

22 World Health Organization. WHO statement on heated tobacco products and the US FDA decision regarding IQOS, 27 Jul 2020. https://www.who.int/news-room/detail/27-07-2020-who-statementon-heated-tobacco-products-and-the-us-fda-decision-regarding-iqos

This is an Open Access article distributed in accordance with the Creative Commons Attribution Non Commercial (CC BY-NC 4.0) license, which permits others to distribute, remix, adapt, build upon this work non-commercially, and license their derivative works on different terms, provided the original work is properly cited and the use is non-commercial. See: http://creativecommons.org/licenses/by$\mathrm{nc} / 4.0 \%$ 